\title{
FORECASTING MONEY DEMAND WITH THE INCLUSION OF FINANCIAL INNOVATION FOR THE ASSOCIATION OF SOUTHEAST ASIAN NATIONS: EVIDENCE FROM PANEL DATA ANALYSIS
}

\author{
Payam Mohammad Aliha ${ }^{1}$ \\ Ph.D student, Universiti Kebangsaan Malaysia (UKM), Malaysia. \\ (Email: payammaliha@gmail.com) \\ Associate Professor Dr. Tamat Sarmidi ${ }^{2}$ \\ Faculty of Economics and Management, Universiti Kebangsaan Malaysia (UKM), Malaysia. \\ (Email: tamat@ukm.edu.my) \\ Associate Professor Dr. Fathin Faizah Said ${ }^{3}$ \\ Faculty of Economics and Management, Universiti Kebangsaan Malaysia (UKM), Malaysia. \\ (Email: fatin@ukm.edu.my)
}

Received date: $17-09-2019$

Revised date: 24-11-2019

Accepted date: $12-12-2019$

Published date: 15-12-2019

To cite this document: Aliha, P. M., Sarmidi, T., \& Said, F. F. (2019). Forecasting Money Demand with The Inclusion of Financial Innovation for The Association of Southeast Asian Nations: Evidence from Panel Data Analysis. Advanced International Journal of Banking, Accounting and Finance, 1 (1), 59-74.

DOI: $10.35631 /$ aijbaf.11006

\begin{abstract}
This paper investigates the impact of financial innovations on the demand for money using a dynamic panel data for 10 ASEAN member states from 2004 to 2012 and attempt to forecast the demand for money during 2013 - 2016 to compare between forecasting performance of the fixed effects model with that of random effects model and also to compare the forecasting accuracy of dynamic forecasting and static forecasting obtained from these two models. An autoregressive model by definition is when a value from a time series is regressed on previous values from that same time series. There are two types of forecasting namely dynamic forecast and static forecast. "Dynamic forecast will take previously forecasted values while static forecast will take actual values to make next step forecast. Panel effects models assist in controlling for unobserved heterogeneity when this heterogeneity is constant over time and correlated (fixed effects) or uncorrelated (random effects) with independent variables. Hausman test indicates that the random-effects model is appropriate. We use the conventional money demand that is enriched with the number of automated teller machines (ATM) to proxy for the effect of financial innovations on money demand. By comparing the magnitude of "Root Mean Squared Error" (RMSE) as a benchmark for the two forecasts (0.1164 for dynamic forecast versus 0.0635 for static forecast) we simply find out that static forecast is superior to dynamic forecast meaning that static forecast provides more accurate forecast compared to a dynamic forecast for the fixed-effects model. Therefore, we conclude the static forecast on the basis of the random-effects model provides the most accurate forecasting. The estimation result of the chosen random-effects regression also indicates the estimated coefficient of ATM is not significant meaning that ATM does not impact money demand in ASEAN countries.
\end{abstract}


Keywords: ASEAN, Money Demand, Random Effects, Fixed Effects, Financial Innovation, Dynamic Panel Data

JEL Classification: C13, C40, C51, E40, E44

\section{Introduction}

In the new environment of modern commerce and technological progress, traditional means of payment is no longer satisfying the need for more convenient, quicker, and more secure means of payment. The evolving commercial models pushed the payment systems constantly to catch up with the requirements of these models and transform into highly sophisticated modern electronic payment instruments. New payment standards were set by the fast growth of digital commerce which has had an impact on the evolution of current electronic payment instruments that in turn has reduced transactional and financial risks. Modern payment systems are crucial in our daily life and in the well-functioning of the economy.

The payment system can be significantly improved by substituting electronic payments for paper-based payments, and therefore, the whole economy is benefited from significant cost savings and efficiency as a result. Substituting cash and cheques by electronic payments, makes it possible to put the resources used in manual processing to their most efficient use thereby reducing the cost of cash and cheque handling a lot. Electronic payment as a more convenient and efficient means of payment, has the capability of improving productivity and lowering the business cost.

The purpose of this study is to examine the impact of financial innovation on money demand using panel data which includes ten ASEAN countries during 2004-2012 for a conclusive result while gaining the most accurate estimates due to the use of the richest dataset. The estimated regression will then be used for the purpose of forecasting during 2013 - 2016 to achieve a comparison between performance power of the fixed effects model and random effects model on one hand and to compare the dynamic forecast and static forecast obtained from each of these models on the other hand.

According to the best of our knowledge, no studies have investigated the forecasting of money demand in ASEAN countries in the context of the best fitted panel data model with the inclusion of financial innovation. Before attempting to forecast money demand for ASEAN countries, it is essential to choose which panel data is suitable for estimating the model that includes proxies to take into account the effect of financial effect on the demand for money in ASEAN countries.

The importance of forecasting can be best described as follow. "Economic forecasts are geared toward predicting quarterly or annual GDP growth rates, the top level macro number upon which many businesses and governments base their decisions with respect to investments, hiring, spending, and other important policies that impact aggregate economic activity. Economic forecasts are very important for determining monetary policy / fiscal policy. If the economy is really expected to recover, then inflation may pick up and the Bank may need to raise interest rates. If the economy is likely to continue to shrink, the Bank may need to pursue further quantitative easing". ${ }^{1}$

\footnotetext{
${ }^{1}$ https://www.investopedia.com/terms/e/economic-forecasting.asp
} 
The results of this study may be of interest to some world organizations such as the World Bank and the International Monetary Fund and the monetary authorities of the ASEAN member states. This study hopes to shed some light on the relationship between ATM and money demand using the most recent data. The rest of the paper includes a literature review followed by methodology and ends up with data analysis and conclusion.

\section{Literature Review}

There are few cross-country studies that have used panel data methods to analyze the money demand function with the inclusion of financial innovations. However, the only researcher who studied money demand in ASEAN countries are Abdullah \& Matahir (2010) who did not include financial innovation in money demand. They only investigate the cointegration property of the money demand using ARDL approach and did not determine how financial innovation affects the demand for money in ASEAN countries. For the effect of the effect of ATM on money demand, few researchers such as Snellma et al. (2001) and Drehmann et al. (2002) conclude a positive effect of ATM on money demand for 10 European countries and for 18 OECD countries, respectively. We briefly review panel data studies according to Chronological order.

Arrau et al (1995) who show that financial innovation in developing countries has a negative impact on the demand for money.

Attanasio et al. (1998) sum up that the demand for money of households who holds an ATM card is much more elastic to interest rate than that of households who do not (based on timeseries and cross-sectional data during 1989 - 1995 in Italy).

Snellma et al. (2001) used panel list squares method based on data for 10 European countries for the period 1987-1996 to estimate demand for money with the conclusion that higher card network coverage and more intensive use of electronic payment instruments reduce the impact on the demand for money and the interest rate elasticity for cash-cards substitution depends on the development of electronic payment infrastructures in each country. The result is also an indication of the existence of a negative relationship between ATM usage and cash balances. In other words, ATMs have reduced the cash demand by the public. Then, they used the estimated elasticities to derive the S-learning curve for the countries under investigation showing similar pattern of the substitutions of cash is similar for the 10 countries and that the diffusion of the card payment infrastructure is the main determinant of the level of the development of each country. The diffusion of both ATM and POS terminals seems to have a negative impact on money balance. Belgium, Finland, France and Denmark have the highest rate of cash substitution (60 percent). The Netherlands and Switzerland are getting started with a fast rate, while Germany, Italy and the UK with a cash rate use of 95 percent, seems to be very slow.

Drehmann et al. (2002) analyse the impact of new payment technologies on the cash demand using annual data for the period 1980 - 1998 in 18 OECD countries with the results that POS terminals are negatively related to the demand for small banknotes while ATMs are positively related to the demand for small notes, although the impact on large notes are ambiguous. They conclude that cash will still play an important role despite the introduction of advanced payment technology. They also find that the number of POS terminals and ATMs have important effects on demand for cash. In short, based on panel data estimations, they find that ATMs will increase cash, but the effect is not highly significant. 
Mark \& Sul (2003) use panel DOLS to estimate coefficients of the long-run money demand function from a panel of 19 countries with annual observations that span from 1957 to 1996. They conclude that the estimated income elasticity is 1.08 and the estimated interest rate semielasticity is -0.02 .

Harb (2004) constructs an aggregate data panel for the GCC's six countries. Pedroni's heterogeneous panel cointegration tests verifies cointegration hypothesis among the variables of the money demand function. He estimate the idiosyncratic, panel and group-mean cointegrating vectors using FMOLS and a modified version of FMOLS developed by Pedroni. The group-mean estimator shows a significant negative semi-elasticity of money demand with respect to interest rate.

Nautz and Rondolf (2010) investigate the money demand for a panel of the Euro Area countries.

Abdullah \& Matahir (2010) examine the demand for money in five ASEAN countries, namely Indonesia, Malaysia, the Philippines, Singapore, and Thailand using the autoregressive distributed lag (ARDL) approach to cointegration analysis. The empirical results show that there is a unique cointegrated and stable long-run relationship among broad monetary aggregate, income, interest rate, exchange rate, foreign interest rate, and inflation. They found that the income elasticity and the exchange rate coefficient are positive while the inflation elasticity is negative. This indicates that depreciation of domestic currency increases the demand for money, supporting the wealth effect argument and people prefer to substitute physical assets for money balances that support our theoretical expectation.

Nagayasu (2012) used the bank concentration data as a measure of financial innovation for his panel data analysis. Bank concentration was measured as a ratio of the number of banks to the total population which presents similarity to using the number of ATMs captured by Fisher (2007).

Hamdi et al. (2014) investigates the money demand function for the Gulf Cooperation Council countries with regard to financial innovations.

Dunne \& Kasekende (2016) investigate the effect of financial innovation on the demand for money in Sub-Saharan Africa using panel data for 34 countries during 1980-2013 and find a negative relationship between financial innovation and money demand. Most importantly, the coefficients of the traditional money demand determinants appear to be sensitive to the addition of financial innovation, with most results showing a decline in coefficients. This may imply that the exclusion of this variable could indeed lead to biased or misleading estimates of the money demand equation.

Sidik, et.al (2018) analyze the impact of financial inclusion on demand for money in 36 countries for the period 2004 to 2014 using a dynamic panel data approach. The result indicates that financial inclusion stimulates the increase of demand for reserve money in developed countries. 


\section{Methodology}

\section{Conventional Money Demand Function}

There are different money demand theories. Each of these theories is based on different ideas and suggests different theoretical hypotheses that can be put to test. Despite differences, however, there are common elements in these theories. One of the most important of these common elements is that they express a relationship between the quantity of money demanded and some variables that are the main determinants of the level of economic activity. The general form of the theory of money demand can be represented as below:

$\frac{\mathrm{M}_{\mathrm{t}}}{\mathrm{P}_{\mathrm{t}}}=\Phi\left(\mathrm{R}_{\mathrm{t}}, \mathrm{Y}_{\mathrm{t}}\right)$

where $\mathrm{M}_{\mathrm{t}}$ is the demand of nominal money balances, $\mathrm{P}_{\mathrm{t}}$ is the price index that is used to convert nominal balances to real balances, $\mathrm{Y}_{\mathrm{t}}$ is the scale variable relating to activity in the real sector of the economy (here, real GDP as the best proxy for such a variable), and $\mathrm{R}_{\mathrm{t}}$ is the opportunity cost of holding money (here, the real interest rate as the best proxy).

We start the empirical estimation of money demand functions with introducing the long-run, $\log$ linear function that is of the form (Serletis, 2007):

$\log \left(\frac{M_{t}^{*}}{P_{t}}\right)=\alpha+\beta_{1} \log Y_{t}+\beta_{2} R_{t}+\varepsilon_{t}$

The conventional money demand $\mathrm{M}^{\mathrm{d}}=\left(\mathrm{Y}_{\mathrm{t}}, \mathrm{R}_{\mathrm{t}}\right)$ is misspecified and leads to the bias that gets into the estimated coefficients. Therefore, it has to be enriched with financial innovation ( $\left.\mathrm{r}^{*}\right)$ so that it can be represented implicitly as $\mathrm{M}^{\mathrm{d}}=\left(\mathrm{Y}_{\mathrm{t}}, \mathrm{R}_{\mathrm{t}}, \mathrm{r}^{*}\right)$ to avoid misspecification of the money demand through over estimation, commonly referred to as "missing money". Failure of cointegration of the money demand can also be attributed to the exclusion of financial innovation (Arrau and De Gregorio, 1991). Autocorrelated errors, persistent over prediction and implausible parameter estimates are examples of issues that arise due to ignoring financial innovation (Arrau et al, 1995). Some of the studies that have accounted for financial innovation in the money demand specification include Arrau and De Gregorio (1993), Ireland (1995), Attanasio et al (2002), Alvarez and Lippi (2009) and Nagayasu (2012).

\section{Empirical Model}

According to previous discussion, we enrich the conventional money demand above with the financial innovation as below:

$\mathrm{LMD}_{\text {it }}=\beta_{0 \mathrm{i}}+\beta_{1 \mathrm{i}} \mathrm{IR}_{\mathrm{it}}+\beta_{2 \mathrm{i}} \mathrm{LGDP}_{\mathrm{it}}+\beta_{3 \mathrm{i}} \mathrm{LATM}_{\mathrm{it}}+\mu_{i t}$

$i=1,2, \ldots, N t=1,2, \ldots, T$

Conventional Demand for Money Function mentioned above is the basis for this specification. We use a traditional specification of the conventional demand for money, where MD denotes currency in circulation, GDP denotes real gross domestic product, IR is the interest rate, ATM is the number of automated teller machines (per 100,000 adults), and $\mathrm{e}_{t}$ is the error term. We then estimate a demand for money in ASEAN countries for the period $2004-2012$ and use the estimated regression to forecast money demand (in logarithm form) for the period 2013 - 2016. 
The expected signs of the coefficients in Equation above are positive for GDP and negative for interest rate (i.e. $\beta_{1}<0$, and $\beta_{2}>0$ ). In addition, the properties of the error sequence $\left(\mu_{i t}\right)$ are an integral part of the theory. This theory assumes that the $\mu_{i t}$ sequence is stationary.

Data for MD, GDP and IR was collected from the official website of the World Bank. The definitions according to the World Bank is as follow:

"GDP (at purchaser's prices) is the sum of gross value added by all resident producers in the economy plus any product taxes and minus any subsidies not included in the value of the products. It is calculated without making deductions for depreciation of fabricated assets or for depletion and degradation of natural resources. GDP is in constant 2011 international dollars (PPP, purchasing power parity). Dollar figures for GDP are converted from domestic currencies using 2010 official exchange rates.

Real interest rate (expressed as percent) is the lending interest rate adjusted for inflation as measured by the GDP deflator.

Broad money (in constant 2011 international dollars, PPP) is the sum of currency outside banks; demand deposits other than those of the central government; the time, savings, and foreign currency deposits of resident sectors other than the central government; bank and traveler's checks; and other securities such as certificates of deposit and commercial paper.

ATM is the number of automated teller machines (per 100,000 adults). Automated teller machines are computerized telecommunications devices that provide clients of a financial institution with access to financial transactions in a public place".

"The Association of Southeast Asian Nations (ASEAN) is a regional intergovernmental organization comprising ten Southeast Asian countries which promotes intergovernmental cooperation and facilitates economic, political, security, military, educational and sociocultural integration amongst its members and other Asian countries, and globally. ${ }^{2}$ Since its formation on 8 August 1967 by Indonesia, Malaysia, the Philippines, Singapore and Thailand, the organisation's membership has expanded to include Brunei, Cambodia, Laos, Myanmar and Vietnam. Its principal aims include accelerating economic growth, social progress, and sociocultural evolution among its members, alongside the protection of regional stability and the provision of a mechanism for member countries to resolve differences peacefully. ASEAN is an official United Nations observer, as well as an active global partner". 3

\section{Panel Estimation Methods}

\section{Qualitative Description}

Random effect models assist in controlling for unobserved heterogeneity when the heterogeneity is constant over time and not correlated with independent variables. This constant can be removed from the data through differencing, for example by taking a first difference which will remove any time invariant components of the model.

Two common assumptions are made about the individual specific effect: the random effects assumption and the fixed effects assumption. The random effects assumption is that the

\footnotetext{
${ }^{2}$ https://en.wikipedia.org/wiki/Association_of_Southeast_Asian_Nations

${ }^{3} \mathrm{https} / / / \mathrm{www}$.futurecitysummit.org/ga/asean-singapore
} 
individual specific effects are uncorrelated with the independent variables. The fixed effect assumption is that the individual specific effect is correlated with the independent variables. If the random effects assumption holds, the random effects model is more efficient than the fixed effects model. However, if this assumption does not hold, the random effects model is not consistent. ${ }^{4}$

\section{Estimation Background}

The basic class of models that can be estimated using a pool object may be written as:

$Y_{i t}=\alpha+X_{i t}^{\prime} \beta_{i t}+\delta_{i}+\gamma_{i}+\varepsilon_{i t}$

Where $Y_{i t}$ is the dependent variable, and $X_{i t}$ is a $k$-vector of regressors, and $\varepsilon_{i t}$ are the error terms for $i=1,2, \ldots, M$ cross-sectional units observed for dated periods $t=1,2, \ldots, T$. The $\alpha$ parameter represents the overall constant in the model, while the $\delta_{i}$ and $\gamma_{i}$ represent crosssection or period specific effects (random or fixed). Identification obviously requires that the $\beta$ coefficients have restrictions placed upon them. They may be divided into sets of common (across cross-section and periods), cross-section specific, and period specific regressor parameters.

While most of the discussion will be in terms of a balanced sample, EViews does not require that data be balanced; missing values may be used to represent observations that are not available for analysis in a given period. The unbalanced case will be detailed only where deemed necessary.

We may view these data as a set of cross-section specific regressions so that we have $M$ crosssectional equations each with $T$ observations stacked on top of one another:

$Y_{i}=\alpha l_{T}+X_{i}^{\prime} \beta_{i t}+\delta_{i} l_{T}+I_{T} \gamma_{i}+\varepsilon_{i}$

For $i=1,2, \ldots, M$, where $l_{T}$ is a $T$-element unit vector, $I_{T}$ is the $T$-element identity matrix, and $\gamma$ is a vector containing all of the period effects, $\gamma^{\prime}=\left(\gamma_{1}, \gamma_{2}, \ldots, \gamma_{T}\right)$.

Analogously, we may write the specification as a set of $M$ period specific equations, each with $T$ observations stacked on top of one another.

$Y_{i}=\alpha l_{M}+X_{i}^{\prime} \beta_{i t}+I_{M} \delta+\gamma_{t} l_{M}+\varepsilon_{i}$

for $t=1,2, \ldots, T$, where $l_{M}$ is a $M$-element unit vector, $I_{M}$ is the $M$-element identity matrix, and $\delta$ is a vector containing all of the cross-section effects, $\delta^{\prime}=\left(\delta_{1}, \delta_{2}, \ldots, \delta_{M}\right)$.

For purposes of discussion we will employ the stacked representation of these equations. First, for the specification organized as a set of cross-section equations, we have:

$Y=\alpha l_{M T}+X \beta+\left(I_{M} \otimes l_{T}\right) \delta+\left(l_{M} \otimes I_{T}\right) \gamma+\varepsilon$

\footnotetext{
${ }^{4}$ https://en.wikipedia.org/wiki/Random_effects_model
} 
where the matrices $\beta$ and $X$ are set up to impose any restrictions on the data and parameters between cross-sectional units and periods, and where the general form of the unconditional error covariance matrix is given by:

$\Omega=E\left(\varepsilon \varepsilon^{\prime}\right)=E\left[\begin{array}{rrrc}\varepsilon_{1} \varepsilon_{1}^{\prime} & \varepsilon_{2} \varepsilon_{1}^{\prime} & \cdots & \varepsilon_{M} \varepsilon_{1}^{\prime} \\ \varepsilon_{2} \varepsilon_{1}^{\prime} & \varepsilon_{2} \varepsilon_{2}^{\prime} & \ddots & \vdots \\ \varepsilon_{M} \varepsilon_{1} & \cdots & & \varepsilon_{M} \varepsilon_{M}^{\prime}\end{array}\right]$

If instead we treat the specification as a set of period specific equations, the stacked (by period) representation is given by,

$Y=\alpha l_{M T}+X \beta+\left(l_{M} \otimes I_{T}\right) \delta+\left(I_{M} \otimes l_{T}\right) \gamma+\varepsilon$

with error covariance,

$\Omega=E\left(\varepsilon \varepsilon^{\prime}\right)=E\left[\begin{array}{rrrc}\varepsilon_{1} \varepsilon_{1}^{\prime}, & \varepsilon_{2} \varepsilon_{1}^{\prime} & \cdots & \varepsilon_{T} \varepsilon_{1}^{\prime} \\ \varepsilon_{2} \varepsilon_{1}^{\prime}, & \varepsilon_{2} \varepsilon_{2}^{\prime} & \ddots & \vdots \\ \varepsilon_{T} \varepsilon_{1}^{\prime} & \cdots & & \varepsilon_{T} \varepsilon_{T}^{\prime}\end{array}\right]$

The presence of cross-section and period specific effects terms $\delta$ and $\gamma$ may be handled using fixed or random effects methods.

You may, with some restrictions, specify models containing effects in one or both dimension, for example, a fixed effect in the cross-section dimension, a random effect in the period dimension, or a fixed effect in the cross-section and a random effect in the period dimension. Note, in particular, however, that two-way random effects may only be estimated if the data are balanced so that every cross-section has the same set of observations.

The fixed effects portions of specifications are handled using orthogonal projections. In the simple one-way fixed effect specifications and the balanced two-way fixed specification, these projections involve the familiar approach of removing cross-section or period specific means from the dependent variable and exogenous regressors, and then performing the specified regression using the demeaned data (see, for example Baltagi, 2005). More generally, we apply the results from Davis (2002) for estimating multi-way error components models with unbalanced data.

Note that if instrumental variables estimation is specified with fixed effects, EViews will automatically add to the instrument list, the constants implied by the fixed effects so that the orthogonal projection is also applied to the instrument list.

The random effects specifications assumes that the corresponding effects $\delta_{i}$ and $\gamma_{i}$ are realizations of independent random variables with mean zero and finite variance. Most importantly, the random effects specification assumes that the effect is uncorrelated with the idiosyncratic residual $\varepsilon_{i t}$.

EViews handles the random effects models using feasible GLS techniques. The first step, estimation of the covariance matrix for the composite error formed by the effects and the residual, uses one of the quadratic unbiased estimators (QUE) from Swamy-Arora, WallaceHussain, or Wansbeek-Kapteyn. Briefly, the three QUE methods use the expected values from 
quadratic forms in one or more sets of first-stage estimated residuals to compute moment estimates of the component variances $\left(6_{\delta}^{2}, 6_{\gamma}^{2}, 6_{\varepsilon}^{2}\right)$. The methods differ only in the specifications estimated in evaluating the residuals, and the resulting forms of the moment equations and estimators.

The Swamy-Arora estimator of the component variances, cited most often in textbooks, uses residuals from the within (fixed effect) and between (means) regressions. In contrast, the Wansbeek and Kapteyn estimator uses only residuals from the fixed effect (within) estimator, while the Wallace-Hussain estimator uses only OLS residuals. In general, the three should provide similar answers, especially in large samples. The Swamy-Arora estimator requires the calculation of an additional model, but has slightly simpler expressions for the component variance estimates. The remaining two may prove easier to estimate in some settings.

Additional details on random effects models are provided in Baltagi (2005), Baltagi and Chang (1994), Wansbeek and Kapteyn (1989). Note that your component estimates may differ slightly from those obtained from other sources since EViews always uses the more complicated unbiased estimators involving traces of matrices that depend on the data. Once the component variances have been estimated, we form an estimator of the composite residual covariance, and then GLS transform the dependent and regressor data.

If instrumental variables estimation is specified with random effects, EViews will GLS transform both the data and the instruments prior to estimation. This approach to random effects estimation has been termed generalized two-stage least squares (G2SLS).

Fixed Effects: If instrumental variables estimation is specified with fixed effect, EViews will automatically add to the instrument list any constants implied by the fixed effect so that the orthogonal projection is also applied to the instrument list. Thus, if $Q$ is the fixed effects transformation operator, we have:

$\beta_{O L S}=\left(\sum_{i} X^{\prime} \mathrm{Q} X_{i}\right)^{-1}\left(\sum_{i} X^{\prime} \mathrm{Q} Y_{i}\right)$

$\beta_{I V}=\left(\sum_{i} X_{i} Q P_{Z_{i}} \mathrm{Q} X_{i}\right)^{-1}\left(\sum_{i} X_{i}^{\prime} Q P_{Z_{i}} \mathrm{Q} Y_{i}\right)$

Where $Z_{i}=\mathrm{Q} Z_{i}$.

Random Effects and GLS: Similarly, for random effects and other GLS estimators, EViews applies the weighting to the instruments as well as the dependent variable and regressors in the model. For example, with data estimated using cross-sectional GLS, we have:

$\beta_{O L S}=\left(\sum_{i} X^{\prime} \Omega_{M}^{-1} X_{i}\right)^{-1}\left(\sum_{i} X^{\prime} \Omega_{M}^{-1} Y_{i}\right) \quad \Omega_{M}^{-1 / 2}$

$\beta_{G I V}=\left(\sum_{i} X_{i} \Omega_{M}^{-1 / 2} P_{Z_{i}} \Omega_{M}^{-1 / 2} X_{i}\right)^{-1}\left(\sum_{i} X_{i}^{\prime} \Omega_{M}^{-1 / 2} P_{Z_{i}} \Omega_{M}^{-1 / 2} Y_{i}\right)$

Where $Z_{i}^{*}=\Omega_{M}^{-1 / 2} Z_{i}$.

In the context of random effects specifications, this approach to IV estimation is termed generalized two-stage least squares (G2SLS) method. Note that in implementing the various random effects methods (Swamy-Arora, Wallace-Hussain, Wansbeek-Kapteyn), we have 
extended the existing results to derive the unbiased variance components estimators in the case of instrumental variables estimation.

More generally, the approach may simply be viewed as a special case of the Generalized Instrumental Variables (GIV) approach in which data and the instruments are both transformed using the estimated covariances. You should be aware that this has approach has the effect of altering the implied orthogonality conditions. ${ }^{5}$

\section{Forecast Evaluation}

When constructing a forecast of future values of a variable, economic decision makers often have access to different forecasts; perhaps from different models they have created themselves or from forecasts obtained from external sources. When faced with competing forecasts of a single variable, it can be difficult to decide which single or composite forecast is "best". Fortunately, there are some tools for evaluating the quality of a forecast which can help one determine which single forecast to use, or whether constructing a composite forecast by averaging would be more appropriate.

Evaluation of the quality of a forecast requires comparing the forecast values to actual values of the target value over a forecast period. A standard procedure is to set aside some history of actual data for use as a comparison sample in which one will compare of the true and forecasted values. It is possible to use the comparison sample to: (1) construct a forecast evaluation statistic to provide a measure of forecast accuracy, and (2) perform Combination testing to determine whether a composite average of forecasts outperforms single forecasts.

There are four different measures of forecast accuracy; RMSE (Root Mean Squared Error), MAE (Mean Absolute Error), MAPE (Mean Absolute Percentage Error), and the Theil Inequality Coefficient. These statistics all provide a measure of the distance of the true from the forecasted values. Suppose the forecast sample is $j=T+1, T+2, \ldots, T+h$, and denote the actual and forecasted value in period $\mathrm{t}$ as $y_{t}$ and $y_{t}$, respectively. The forecast evaluation measures are defined as table below. ${ }^{6}$

\footnotetext{
${ }^{5}$ https://eviews.com/help/content/panel-Estimation_Background.html

${ }^{6}$ https://eviews.com/help/content/series-Forecast_Evaluation.html
} 
Table 1: The Forecast Evaluation Measures

\begin{tabular}{ll}
\hline Measure & Statistics \\
\hline Root Mean Squared Error & $\sqrt{\sum_{t=T+1}^{T+h}\left(y_{t}-y_{t}\right)^{2} / h}$ \\
Mean Absolute Error & $\sum_{t=T+1}^{T+h}\left|y_{t}-y_{t}\right| / h$ \\
Mean Absolute Percentage Error & $100 \sum_{t=T+1}^{T+h}\left|\frac{y_{t}-y_{t} \mid}{y_{t}}\right| / h$ \\
Theil Inequality Coefficient & $\frac{\sqrt{\sum_{t=T+1}^{T+h}\left(y_{t}-y_{t}\right)^{2} / h}}{\sqrt{\sum_{t=T+1}^{T+h}\left(y_{t}\right)^{2} / h+\sqrt{\sum_{t=T+1}^{T+h}\left(y_{t}\right)^{2} / h}}}$ \\
\hline
\end{tabular}

\section{Data Analysis}

We use data on money demand, gross domestic product, interest rate (all in real terms) and the number of automated teller machines (to proxy the effect of financial innovation) in the context of a conventional money demand function for a panel of 10 countries in ASEAN economic zone. Then we use fixed effects and random effects models and use the estimated results for the purpose of forecasting. Finally, we compare between static forecast and dynamic forecast for each of these models (fixed effects model and random effects model).

The fixed effects or LSDV model allows for heterogeneity or individuality among the 10 countries by allowing them to have their own intercept values. The term fixed effects is due to the fact that although the intercept may differ across countries, but it does not vary over time, that is, it is time invariant. The random effects model assumes that the individual specific effects are not correlated with the independent variables.

Table 2: Cross-Section Fixed Effects Regression Model Estimates

\begin{tabular}{crrrr}
\hline \hline Variable & Coefficient & Std. Error & t-Statistic & Prob. \\
\hline \hline C & -1.468279 & 2.834006 & -0.518093 & 0.6061 \\
LGDP & 0.312330 & 0.147351 & 2.119627 & 0.0378 \\
IR & 0.007389 & 0.001632 & 4.526750 & 0.0000 \\
LATM & 0.025390 & 0.012687 & 2.001282 & 0.0495 \\
LMD(-1) & 0.737732 & 0.073444 & 10.04483 & 0.0000 \\
\hline \hline \multicolumn{5}{c}{ Effects Specification } \\
\hline \hline Cross-section fixed (dummy variables) & \\
\hline \hline & & & \\
R-squared & 0.998622 & Mean dependent var & 25.54452 \\
Adjusted R-squared & 0.998350 & S.D. dependent var & 1.851261 \\
S.E. of regression & 0.075193 & Akaike info criterion & -2.179889 \\
Sum squared resid & 0.373163 & Schwarz criterion & -1.763034 \\
Log likelihood & 101.1955 & Hannan-Quinn criter. & -2.012760 \\
F-statistic & 3678.453 & Durbin-Watson stat & 2.375751 \\
Prob(F-statistic) & 0.000000 & & \\
\hline \hline
\end{tabular}


The coefficient of LATM is significant while bearing the positive sign. The statistics (Prob > F) indicates that all the coefficients in the model are different from zero as it is less than 0.05 . Now, we shall forecast the dependent variable which is LMD and compare the forecasted dependent variable with actual dependent variable.

Our data is from 2004 to 2016 (for a panel of 10 ASEAN countries). Out of this, we shall be using data from 2004 to 2012 (also called sample) for estimated regression line. Data from 2013 to 2016 shall be used for forecasting. Regarding the fact that all data are known, we call it ex-post forecasting. Our forecast will be based on an autoregressive model. An autoregressive model by definition is when a value from a time series is regressed on previous values from that same time series.

There are two types of forecasting namely dynamic forecast and static forecast. "Dynamic forecast will take previously forecasted values while static forecast will take actual values to make next step forecast. Dynamic forecast uses the value of the previous forecasted value of the dependent variable to compute the next one".

\section{Table 3: Dynamic Forecast}

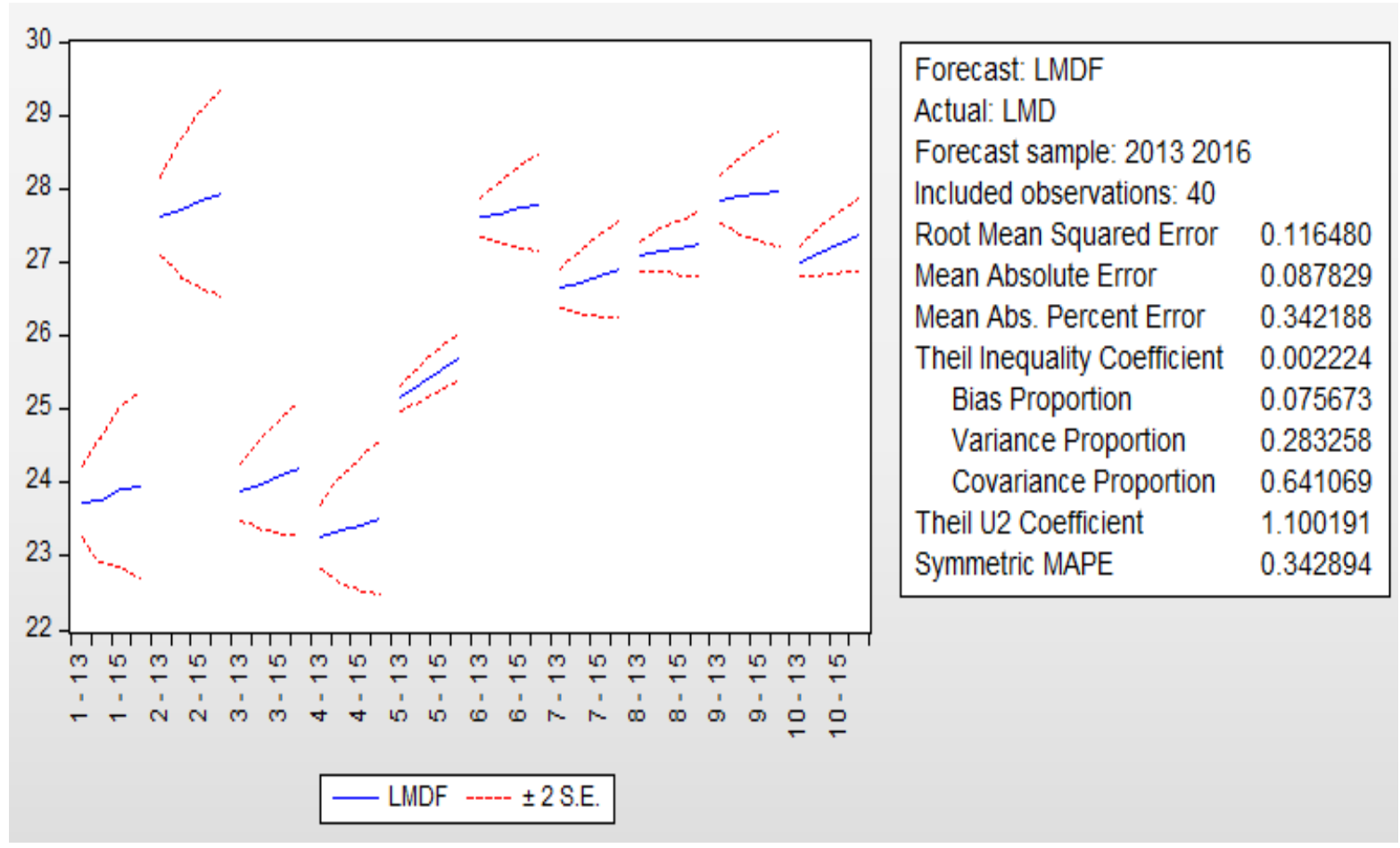


Table 4: Static Forecast

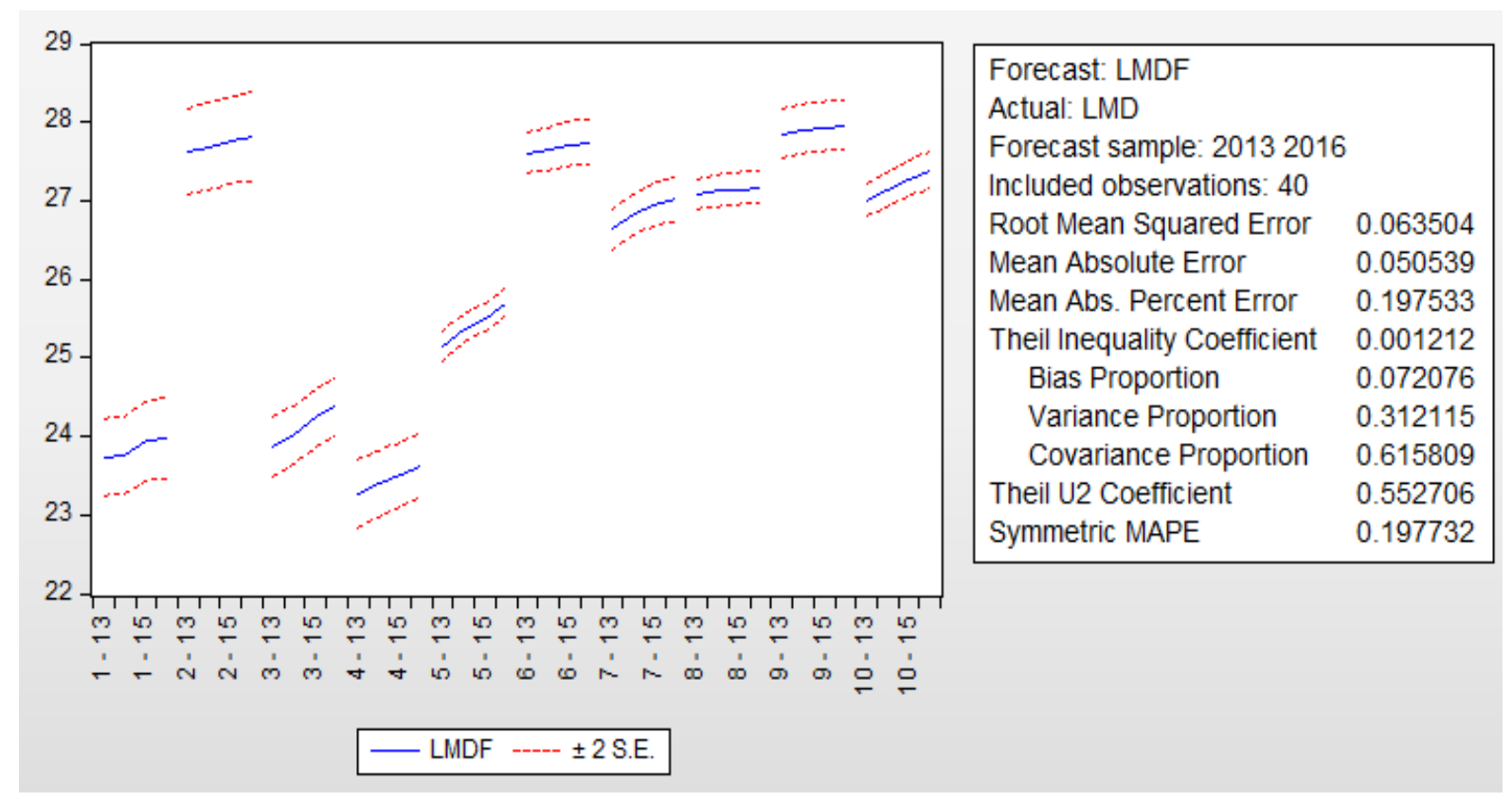

As can be seen, the forecasted dependent variable in both figures is passing through 95 percent confidence intervals or between two standard deviations in dynamic and static forecasts. For the purpose of forecast evaluation, first we choose "Root Mean Squared Error" (RMSE) as benchmark. This statistic refers to the gap between forecasted LMD and actual LMD. Smaller RMSE means better forecasting or more predictive power. By comparing the magnitude of this statistic for the two forecasts ( 0.1164 for dynamic forecast versus 0.0635 for static forecast) we simply find out that static forecast is superior to dynamic forecast meaning that static forecast provides more accurate forecast compared to dynamic forecast for fixed effects model. Now, we turn our attention to the forecasts from random effects model.

Table 5: Cross-Section Random Effects (Panel EGLS) Estimates

\begin{tabular}{|c|c|c|c|c|}
\hline Variable & Coefficient & Std. Error & t-Statistic & Prob. \\
\hline $\mathrm{C}$ & -0.207835 & 0.234505 & -0.886270 & 0.3783 \\
\hline LGDP & 0.013671 & 0.032435 & 0.421486 & 0.6746 \\
\hline IR & 0.009573 & 0.001403 & 6.825150 & 0.0000 \\
\hline LATM & -0.004936 & 0.005288 & -0.933494 & 0.3536 \\
\hline $\operatorname{LMD}(-1)$ & 0.996224 & 0.028611 & 34.81922 & 0.0000 \\
\hline \multicolumn{5}{|c|}{ Effects Specification } \\
\hline & & & S.D. & Rho \\
\hline Cross-section random & & & 0.021081 & 0.0729 \\
\hline Idiosyncratic random & & & 0.075193 & 0.9271 \\
\hline \multicolumn{5}{|c|}{ Weighted Statistics } \\
\hline R-squared & 0.996908 & \multirow{5}{*}{\multicolumn{2}{|c|}{$\begin{array}{l}\text { Mean dependent var } \\
\text { S.D. dependent var } \\
\text { Sum squared resid } \\
\text { Durbin-Watson stat }\end{array}$}} & 20.01521 \\
\hline Adjusted R-squared & 0.996743 & & & 1.459991 \\
\hline S.E. of regression & 0.083316 & & & 0.520611 \\
\hline F-statistic & 6046.040 & & & 2.145924 \\
\hline Prob(F-statistic) & 0.000000 & & & \\
\hline
\end{tabular}


The coefficient of LATM is negative but insignificant. F-statistic confirms that the model is overall significant. Next, we use this estimated regression for the purpose of forecasting.

\section{Table 6: Dynamic Forecast}

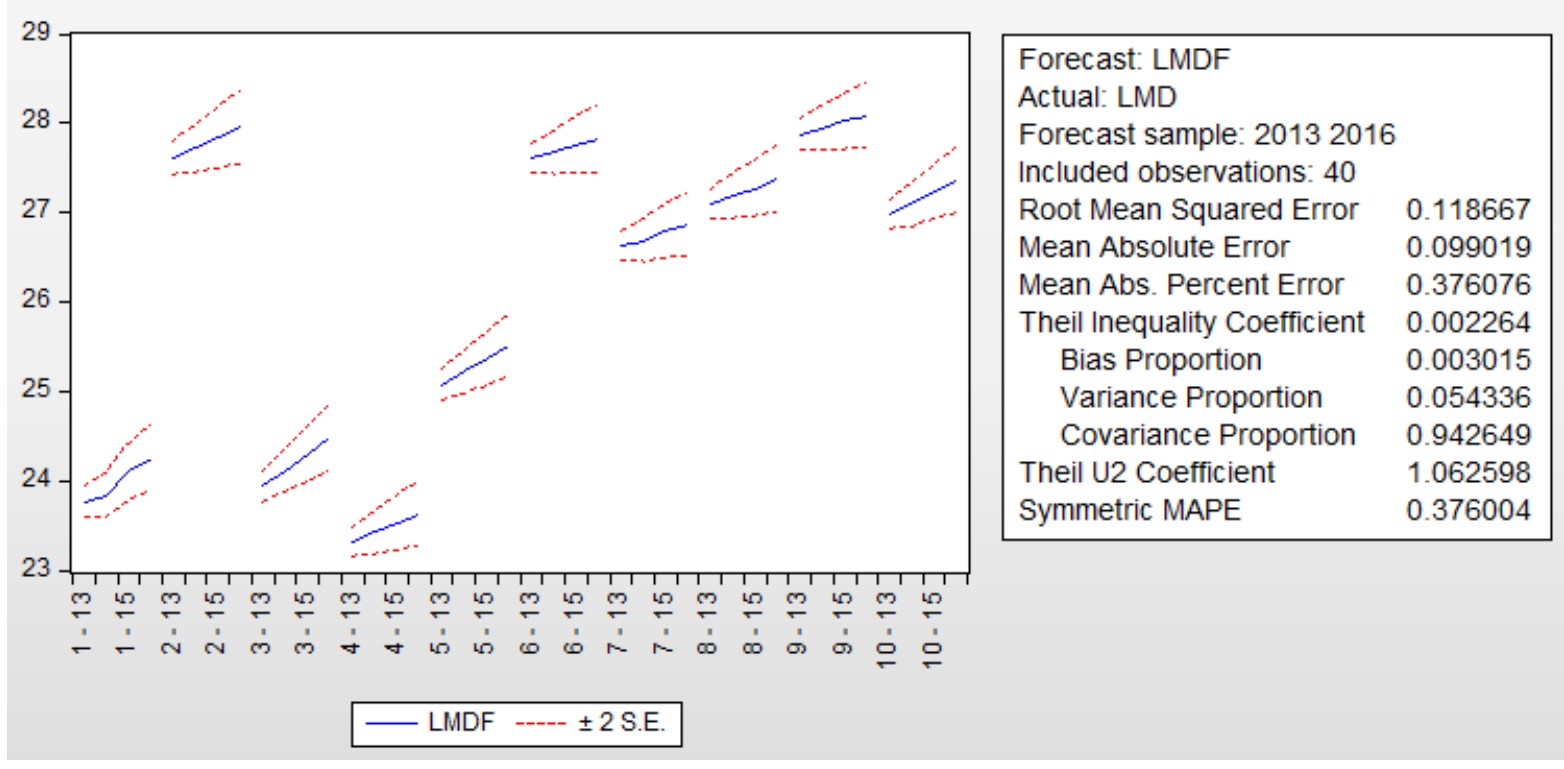

Table 7: Static Forecast

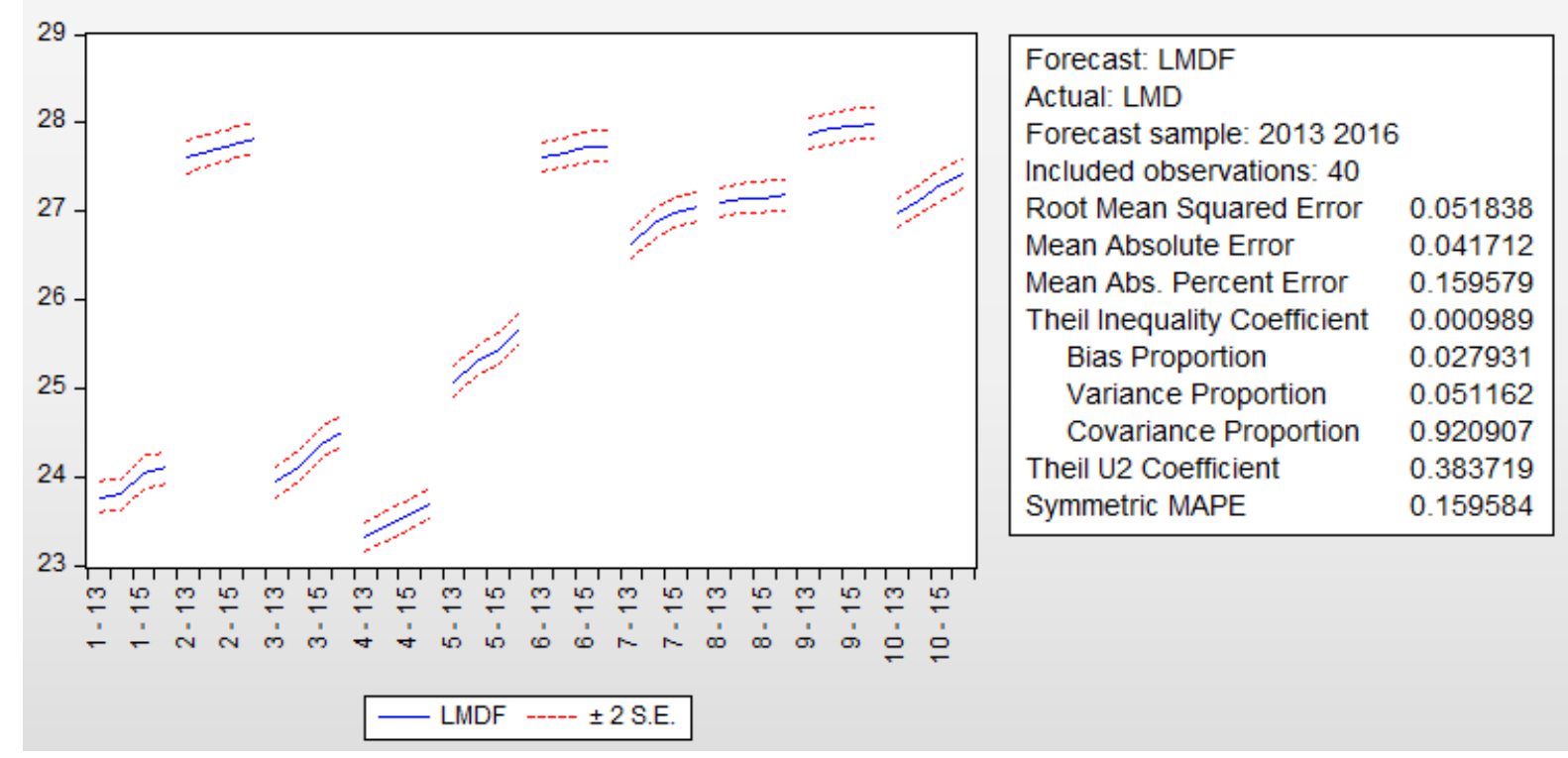

Again, it is clear that on the basis of random effects model, static forecast is more accurate and powerful than that of dynamic forecast.

To decide between fixed or random effects model, we run a Hausman test (see Table 7). It basically tests whether the unique errors are correlated with the regressors, the null hypothesis is they are not. 
Table 8: Hausman Test (Hausman Random)

\begin{tabular}{lrrr}
\hline \hline Test Summary & Chi-Sq. Statistic & Chi-Sq. d.f. & Prob. \\
\hline \hline Cross-section random & 21.078443 & 4 & 0.0003 \\
\hline \hline
\end{tabular}

We reject null (fixed effect is appropriate) so we conclude that random effects model is appropriate. The overall conclusion is that static forecast (based on random effects model) provides the most accurate forecast.

\section{Conclusion}

We summarize the paper as follow. The random effects assumption is that the individual specific effects are uncorrelated with the independent variables. The fixed effects assumption is that the individual specific effect is correlated with the independent variables. Hausman test was used to find out which model is appropriate, fixed effects model or random effects model. The test result indicates that the random effects model is appropriate. The coefficient of LATM in the chosen random effects model is negative yet insignificant.

However, the main focus of the paper is to make a comparison between dynamic forecasting and static forecasting. In both fixed effects and random effects model, static forecast is more accurate than dynamic forecast based on a benchmark called "Root Mean Squared Error" (RMSE). Regarding the fact that the random effects model is appropriate, we choose this model for forecasting. The final decision is that on the basis of random effects model, static forecast outperforms the dynamic forecast for our case study.

\section{References}

Abdullah, H., Ali, J. \& Matahir, H. 2010. Re-Examining the Demand for Money in Asean5 Countries. Asian Social Science 6(7): 146.

Alvarez, F. \& Lippi, F. 2009. Financial Innovation and the Transactions Demand for Cash. Econometrica 77(2): 363-402.

Arrau, P., De Gregorio, J., Reinhart, C. M., \& Wickham, P. (1995). The demand for money in developing countries: assessing the role of financial innovation. Journal of Development Economics, 46(2), 317-340.

Arrau, P. \& De Gregorio, J. 1993. Financial Innovation and Money Demand: Application to Chile and Mexico. The Review of Economics and Statistics 524-530.

Arrau, P. \& De Gregorio, J. 1991. Financial Innovation and Money Demand: Theory and Empirical Implementation. 585. World Bank Publications.

Attanasio, O. P., Guiso, L. \& Jappelli, T. 2002. The Demand for Money. Financial Innovation

Attanasio, O., Guiso, L., \& Jappelli, T. (1998). The demand for money, financial innovation, and the welfare cost of inflation: An analysis with household data: National Bureau of Economic Research.

Baltagi, B. (2008). Econometric analysis of panel data: John Wiley \& Sons.

Drehmann, M., Goodhart, C., \& Krueger, M. (2002). The challenges facing currency usage: will the traditional transaction medium be able to resist competition from the new technologies? Economic Policy, 17(34), 193-228.

Harb*, N. 2004. Money Demand Function: A Heterogeneous Panel Application. Applied Economics Letters 11(9): 551-555. 
Hamdi, H. \& Sbia, R. 2014. Empirical Evidence on the Long-Run Money Demand Function in the Gcc Countries.

Ireland, P. N. 1995. Endogenous Financial Innovation and the Demand for Money. Journal of Money, Credit, and Banking 27(1): 92-93.

J Paul Dunne and Elizabeth Kasekende. (2016). Financial Innovation and Money Demand: Evidence from Sub-Saharan Africa. ERSA working paper.

Mark, N. C. \& Sul, D. 2003. Cointegration Vector Estimation by Panel Dols and Long-Run Money Demand. Oxford Bulletin of Economics and statistics 65(5): 655-680.

Nagayasu, J. 2012. Financial Innovation and Regional Money. Applied Economics 44(35): 4617-4629.

Nautz, D. \& Rondorf, U. 2011. The (in) Stability of Money Demand in the Euro Area: Lessons from a Cross-Country Analysis. Empirica 38(4): 539-553.

Serletis, A. (2007). The demand for money: Theoretical and empirical approaches: Springer Science \& Business Media.

Sidik, Z. N., Achsani, N. A. \& Pasaribu, S. H. 2018. Financial Inclusion and Demand for Money: A Dynamic Panel Data Approach. Signifikan: Jurnal Ilmu Ekonomi 7(2):

Snellman, J. S., Vesala, J. M., \& Humphrey, D. B. (2001). Substitution of noncash payment instruments for cash in Europe. Journal of Financial Services Research, 19(2-3), 131145. 